\section{Darryl Francis: Maverick in the Formulation of Monetary Policy}

\author{
Jerry L. Jordan
}

D arryl Francis retired from this Reserve Bank almost a quarter century ago, but his imprint on the culture and reputation of the Bank endures to the present time. Before I left the Bank, and for some time after, people would ask about him and I found that all immediately understood when I answered, "Darryl is the Harry Truman of the Federal Reserve."

I don't know what it is about someone with a rural background, and a disarmingly friendly nature, from the "Show Me State" that causes him to be so clear minded and resolute in his convictions. Both for himself and his staff, Darryl lived true to the expression, "First be sure you are right, then go ahead." This fostered the ideal atmosphere for a balanced emphasis on economic theory and empirical research.

Darryl Francis was already president of this Bank when I joined the research staff at the invitation of Homer Jones, its venerable research director. For any Reserve Bank economist captivated by monetary policy issues, the nature of the Bank's president is bound to be a crucial matter. In my case, Darryl Francis nurtured the ideal environment for someone in transition from academic studies to hands-on policy advising. In addition to monetary policy, Darryl was interested in the effectiveness and efficiency of all aspects of our central bank mission.

A couple of years after I came here, he sent me off into exile to run the data processing and other departments. Exile was not punishment, rest assured, but it was in the nature of missionary work on behalf of economists, among others. At that time computers scarcely had surfaced in System research departments. The Banks' computers were used for processing checks and accounting records, and their design would have to be rethought in the light of growing demands to run regressions, maintain data banks, and, poten-

Jerry L. Jordan is the president and chief executive officer of the Federal Reserve Bank of Cleveland. tially, operate the increasingly popular large models of the economy. These models, containing hundreds of equations, were making inroads with the Board of Governors' research staff, who were hoping to assist in formulating and implementing monetary policy by opening many of the black boxes that connect monetary and fiscal policy tools to the ultimate objectives.

As everyone knows, St. Louis did not follow the Board down the path of gargantuan models of the economy. Instead, we focused on direct empirical tests of rival conjectures about monetary and fiscal impulses, as exemplified by what became known as the St. Louis model, which is associated with an article that Leonall Andersen and I published in the Bank's Review in 1968.

Darryl Francis was indeed a monetary policy maverick. But let me first explain the sense in which I use the term "maverick," for the word has several meanings. The old Webster's unabridged dictionary in the Cleveland Reserve Bank library explains that the word can be traced to one Sam Maverick, a Texas rancher of the mid-nineteenth century who refused to brand his cattle. On that account, unbranded, stray cattle came to be called "mavericks" and were considered the property of the first person who branded them. Clearly, this is not my meaning. Darryl Francis never allowed himself to be appropriated and branded by any person or group.

The second dictionary definition of maverick is simply a person who has "escaped from the herd." This, too, is not my meaning. Darryl Francis did, in fact, escape from the Federal Reserve herd in 1949 to spend five years in private sector banking. But then he rejoined the Fed in 1953 and remained until he had spent 10 years leading the St. Louis herd as president of this Bank.

A third definition comes closer to my intended usage: "an independent," but a fourth hits the nail on the head. This defines a maverick as "an independent individual who refuses to conform with his group."

Now, some might say that Darryl Francis was a conformist, not a maverick. That is, he conformed to the image of St. Louis Reserve Bank presidents as mavericks, for he was not the first. Delos C. Johns, president of this Bank from 1951 to 1962 , is said to have been chosen for the job in part because he could be counted on to nettle William McChesney Martin, Jr., Chairman of the Board of Governors and of the Federal Open Market Committee (FOMC) 
from 1951 until 1970. McChesney Martin himself, of course, started his career as an examiner here at the St. Louis Fed. Even earlier than that, according to Milton Friedman, Chairman Martin's father, William McChesney Martin, Sr., displayed a maverick's instinct in open market committee meetings while he was governor of this Bank from 1929 to 1941 . But I digress.

Foremost among the groups with which Darryl Francis refused to conform, of course, was the FOMC. His record is clear. He participated in well over one hundred FOMC meetings and was a voting member of the Committee for three years in this Bank's rotation with the Atlanta and Dallas Reserve Banks. During those voting periods of 1967-68, 1970-71, and 1973-74, he dissented from the Committee's decision more than one-third of the time, at 13 meetings. More than that, he was alone is his dissents on 8 of those 13 occasions. This is a brave man.

Darryl became president of the Bank in January of 1966, but he didn't become a voting member of the Committee until March of 1967. By the time of his third vote, at the May meeting, he struck out on the path he was to follow for the remainder of his term as president. He dissentedalone among the 12 members of the Committeein favor of what history surely must judge to have been a better direction than the other members chose. He dissented three more times in that first voting year, each time arguing that the Committee's anticipated paths of money and bank credit were more expansionary than would be consistent with an already expansionary fiscal policy and with the renewed economic expansion that could be expected that year and thereafter.

It would have been difficult to engage the Committee in a meaningful discussion of this alternative point of view because the members displayed no visible commitment to a common strategic target such as maintaining a stable purchasing power of the dollar. This "incoherence," as Bill Poole recently called it, shows through in the directives to the trading desk for the conduct of monetary policy during inter-meeting periods. They simply reflected the news of the day, evolving from meeting to meeting.

The policy of the first meeting of 1967 was to be "conducive to non-inflationary economic expansion while recognizing the need for progress toward reasonable equilibrium in the country's balance of payments." The next three meetings sought to be "conducive to combating the effects of weakening tendencies in the economy." At the May meeting the Committee wanted to be "conducive to renewed economic expansion." In July, "renewed" became "continuing" and the balance of payments concern for the remainder of the calendar year became "recognizing the need for reasonable price stability for both domestic and balance of payments purposes." In August, the Committee switched from "continuing" economic expansion to "sustainable" economic expansion.

By the time of the November 1967 meeting, inflation was taking its toll on the viability of the dollar exchange standard and the Bretton Woods international monetary system. The British had devalued the pound sterling by 50 percent, the President of the United States was compelled to publicly reiterate that the United States intended to maintain the \$35-per-ounce peg to gold, and the Fed had raised the discount rate half a percent. The Committee described this as a period of market "turbulence" and gave no pretence of strategic objective. It merely stated a desire to facilitate orderly adjustments to the increased discount rate. A month later, the Committee changed course again, stating its policy was to "foster financial conditions conducive to resistance of inflationary pressures and progress toward reasonable equilibrium in the country's balance of payments." In January 1968, resisting inflationary pressures remained, but the policy went back to "progress toward reasonable equilibrium in the country's balance of payments."

I have a sense of déjà vu when I compare FOMC post-meeting press releases of 1997 through 1999 with the directives of 1967 and 1968, for they both simply describe the evolving reaction of the Committee to incoming information. In that earlier period, the Committee apparently had become so accustomed to the post-Accord experience of price stability that they simply assumed it would take care of itself while they tried to fine-tune the economy. Meanwhile, the rest of the world began to pile up unwanted dollar balances.

Such policy incoherence must be avoided today, and-as of the beginning of 2000-the FOMC has tried to avoid it by changing the content of its press releases. Each release now reminds both the Committee and the public of its continuing strategic policy objective, stating, "Against the background of its long-run goals of price stability and sustainable economic growth and of the information 
currently available, the Committee believes" whatever it decides to say about the period until its next meeting.

When Darryl started his second tour of duty as a voting member of the Committee, Arthur Burns had become Chairman just the month before. The directive began to show signs that Darryl was no longer alone in his concern for a more strategic approach to policy decisions. The objectives of the Committee, as stated in the directive, remained unchanged from meeting to meeting: to "foster orderly reduction in the rate of inflation, while encouraging the resumption of sustainable economic growth and attainment of reasonable equilibrium in the country's balance of payments."

Who knows? Perhaps these three objectives might have been jointly attainable in the long run, but for the short run they sound more like motherhood and apple pie. In the monetarist tradition of the St. Louis Bank, it might have been preferable to choose a money growth rate as an instrument for achieving the strategic objectives. Nonetheless, at least the Committee said it was guided by a constant constellation of major stars in 1970 and 1971, rather than focussing on every starlet going down the street.

More evidence of the Committee's movement toward the maverick from St. Louis comes from the second operating instruction paragraph of the directive. Initially, it merely stated an objective for money market conditions thought to be consistent with expected growth paths of money and credit. Frequently, this was conditioned on smoothing the path for Treasury financing. Sometimes it even was conditioned on evidence that money and credit actually were following the Committee's expected paths. Darryl dissented in May 1970 because the Committee's expected paths for M1 growth seemed excessive.

Then the Committee took time out to deal with a commercial paper crisis caused by the bankruptcy of the Penn Central railroad. Concrete evidence of movement came in December when the Committee identified M1 as what it meant when it mentioned money. This step toward the maverick from St. Louis did not prevent Darryl from dissenting. Having specified M1 as money, he wanted less emphasis on bank credit. In addition, he preferred a lower rate of $M 1$ growth. He dissented again at the January 1971 meeting and also at the February meeting, which was the last of his second voting term. He wanted less emphasis on money market conditions in the operational instruction to the Trading Desk in New York.

A lot happened in the next two years. The United States imposed wage and price controls in a futile attempt to reduce inflation. It abandoned official convertibility of the dollar into anything, even for other central banks. And it devalued the dollar twice in 14 months, from a nominal gold content of ${ }^{1 / 35}$ of an ounce to $1 / 42$ of an ounce.

As Darryl began his third term as a voting member, the Committee appeared to have moved further in his direction, at least superficially. The directive's operational paragraph now instructed the Desk to maintain bank reserves and money market conditions consistent with expected paths, or ranges, of M1 and M2. By the end of the year, this operational instruction had become more sharply defined, stating a range within which the Desk might move the funds rate in response to movements of the growth rates of M1 and M2 within allowable ranges.

In retrospect, this seems to have been closer to a shell game than to an effective operating procedure. That assessment might have been clear to Darryl Francis at the July and August 1973 FOMC meetings. In dissenting from the Committee's instruction to the Desk at both of those meetings, he pointed out that the growth ranges for M1 and M2 were inconsistent with the constraint placed on movements in the funds rate.

Nonetheless, the procedure might have worked had the Committee relaxed its constraint on the funds rate when inconsistencies became apparent, but that was almost never the case. The December 1973 meeting was a classic example. The oil crisis was on; price pressures were apparent. Seeking the best of both worlds, the Committee announced a new strategic objective: policy was to resist inflationary pressures and, at the same time, to cushion the effects on production and employment growing out of the oil shortage. The directive called for some easing in bank reserves and money market conditions, provided that the monetary aggregates did not appear to be growing excessively. By early January 1974, the Committee was asked to increase the inter-meeting limit on additions to the System Open Market Account (SOMA) portfolio that became necessary to accommodate excessive growth in the aggregates. The majority agreed; Darryl Francis dissented, arguing that banks should be forced to borrow the needed extra reserves.

A week later, with the funds rate at the top of 
its allowable range and the aggregates above the tops of their allowable ranges, the Committee members had to choose which constraint to honor. The majority agreed to obey the funds rate constraint, rather than the monetary aggregate constraint. Darryl Francis dissented. The rest is history. Not until 1979 did the Committee finally become persuaded that inflation was a monetary phenomenon - that unless the growth of money was brought down, the rate of inflation could not be brought down. What might have been a modest economic adjustment to lower money growth after the petroleum crisis in 1973-74 in fact became the very painful adjustment of 1979-82.

On reflection, Darryl Francis's three-year maverick voting record reveals a distinct pattern. In 1967-68, the Committee had no apparent anchor to its decisions - not even maintaining the viability of the international dollar standard. Darryl pointed to an anchor - a stable trend growth rate of M1 that was consistent with price stability. By 1970-71, the Committee was moving in his direction, with an unchanging set of strategic objectives and operating expectations for M1 and M2 growth. By 1973-74, the Committee faced the inconsistency between its operating objectives for M1 and M2 and the operating procedure it used to attain those objectives. Despite Darryl Francis's dissents, which pointed out that the procedural emperor had no clothes, the Committee went naked into most of the remainder of the decade, setting an interest rate without reckoning with the inflationary consequences. To switch metaphors, push had come to shove, and, until 1979, the Committee shoved along the path Darryl Francis had tried to push them off.

I find several parallels between Darryl Francis's FOMC voting experience and more recent FOMC experience. One is the importance to the Committee and to each potential maverick on the Committee of maintaining an overriding strategic objective for price stability. Unfortunately, as time passed, Darryl's lessons about monetary targets seem to have become impossible to apply. At present, the simple and appealing concept of "money" has no generally accepted empirical surrogate that can serve as a strategic objective or an operating guide for policy.

It is true, however, that we have been making progress over the past decade in rebuilding a regime in which people believe that any increase in inflation and interest rates is temporary, and that the longer-term trend is toward price stability. Nevertheless, an unfortunate tendency persists in the financial press to assert that the Fed seeks to slow growth in order to prevent inflation-in spite of every current FOMC member having declared that growth does not cause inflation and that the ultimate objective of monetary policy is to maximize long-run growth by preserving a stable purchasing power of money.

Declaring that growth does not cause inflation did not prevent some Fed-watchers from viewing each increase in the Committee's funds rate target in 1999 and 2000 as a potential assault on the longevity of the longest economic recovery on record. In my view, however, the environment of rapid technological innovation and increased productivity had a crucial impact on monetary policy that must be recognized if we are to understand a second parallel to Darryl Francis's maverick tenure on the FOMC: Raising a nominal overnight interbank rate does not necessarily ensure a restrictive policy. In the 60s and 70s, policy was not restrictive because the inflation premium in interest rates was rising faster than the Committee was raising the overnight policy rate. In the 1999-2000 environment, raising the overnight policy rate did not indicate that the stance of policy had become more restrictive if the real return to capital was rising faster than the policy rate. Let me explain.

All of us probably are familiar with the idea that household consumption behavior tends to reflect expectations about longer-term ability to consume. This phenomenon has been called the life-cycle hypothesis, standard or standardized income, and, of course, permanent income by Milton Friedman in the Theory of the Consumption Function.

The basic idea is familiar. Transitory changes in measured income or cash flow fluctuate around some longer-term average; household consumption behavior does not fully reflect these transitory changes in the short run. Sharp increases in measured income are not fully reflected in corresponding increases in current consumption-nor are sudden rapid declines in measured income reflected in corresponding declines in consumption spending.

Both the theoretical framework and empirical observations traditionally suggest that permanent income is relatively steady, while transitory changes in measured income are more variable. However, it can also be the case that periods of rising produc- 
tivity and significant technological innovation produce a generalized perception that permanent income is rising relative to measured income.

People may come to form this expectation in a variety of ways. Sustained periods of steady employment and growing paychecks may lead people to expect that not only has their real standard of living risen, but it will continue to rise in the future-possibly at a faster rate than previously expected. Or, they may come to expect fewer or shorter periods of unemployment. Or, they may observe that their $401 \mathrm{~K}$ savings plans or definedcontribution retirement programs now promise a higher future stream of income than previously thought. In a variety of ways, people come to expect that they will be able to consume more in the present, as well as in the future, than they previously thought.

As a result of any (or some combination) of these various forces in the "new economy" environment, households perceive that their long-term ability to consume is higher. In economists' language, they have moved to a higher indifference curve.

In the business or entrepreneurial sector, rising productivity and an enhanced pace of technological innovation mean that the marginal efficiency of capital is higher. Again in economists' jargon, the production possibility boundary has both shifted out and changed its shape, offering more tomorrow in return for giving up consumption today. Real interest rates rise as new opportunities bring a higher rate of return on new business investment.

These higher real interest rates are not a matter of policy choice or of anyone's discretion. Rather they are a manifestation of economic forces that result in better uses for available productive resources. With households and businesses both increasing their claims on current productive resources, real interest rates must rise in competitive markets.

Higher real interest rates need not imply higher nominal interest rates. Just to exclude complications for the moment, consider the case under a gold standard. Increased productivity and technological innovation would exert downward pressure on the prices of some goods. Institutionalized monetary stability implied by a gold standard means that the price level falls. Thus, the purchasing power of money rises in the face of greater productivity.

The falling price level means that greater permanent real income can be distributed to society with the same level of nominal income. The falling price level also implies that unchanged nominal interest rates, or possibly even somewhat lower nominal interest rates, correspond to higher real interest rates. These higher real rates are the essential market mechanism by which competition between consumers and investors rations present consumption against augmented future consumption.

But we're not on a gold standard. What happens in a discretionary monetary policy regime using an interest-rate-pegging procedure? The upward pressure on real interest rates that is a necessary consequence of greater productivity and the faster pace of technological innovation initially puts upward pressure on nominal interest rates. Greater and greater injections of central bank money then are necessary to keep the pegged level of the nominal overnight interbank rate unchanged. Rising market interest rates mean that the opportunity cost of holding money balances is rising. That, in turn, means the quantity of money demanded declines and the income velocity of money rises. This combination of a higher trend growth of velocity and the faster growth of central bank money means that a higher rate of nominal finaldemand growth is accommodated by a more expansionary rate of money growth.

In such an environment the increase in nominal interest rates-while initially reflecting upward pressure on real interest rates-will be augmented by a rising inflation premium. The overnight interbank rate is under persistent upward pressure so long as it continues to lag behind market-determined interest rates.

This dynamic process describes an environment in which acceleration in the pace of technological innovation and productivity can inadvertently become an inflationary process. The central bank's passive maintenance of an unchanged overnight rate accommodates nominal price increases by failing to accommodate real interest rate increases. As a result, credit markets are unable to play their role in rationing available real productive resources amongst heightened competing demands that reflect the increased return to real capital.

If that description of policymaking in a period of accelerating productivity growth makes me seem like a maverick, I'm happy to wear the label.

This brings me to the third and final parallel I see between Darryl Francis's experience with policy implementation and today's experience. 
Each member of the Committee is, by design, an independent free agent. While the will of the majority always prevails, each member must be prepared respectfully to disagree. As Darryl demonstrated, the maverick, the dissenter, the sometimes-lonely voice in the crowd, plays a vital role in the continuing evolution of policy thinking and policy making. We all salute him for his courage during an exceptionally challenging period of our central bank's history. 